\title{
GASTROPROTECTIVE EFFECT OF AQUEOUS EXTRACT OF AZADIRACHTA INDICA (NEEM) ON ETHANOL INDUCED GASTRIC LESION IN RATS
}

\author{
RIFAYET RAHMAN ${ }^{1}$, ISMAIL KHAN ${ }^{2}$, MAHBUBUL HOQUE ${ }^{3}$, MUQBULA TASRIN AKTAR ${ }^{4}$, ZINAT REHANA SHARMIN ${ }^{5}$ \\ ${ }^{1}$ Assistant Professor, Dept. of Pharmacology, Green Life Medical College, Dhaka \\ ${ }^{2}$ Professor, Dept. of Pharmacology, Dhaka Medical College, Dhaka \\ ${ }^{3}$ Lecturer, Dept. of Pharmacology, Popular Medical College, Dhaka \\ ${ }^{4}$ Lecturer, Dept. of Pharmacology, Shaheed Suhrawardi Medical College, Dhaka \\ ${ }^{5}$ Lecturer, Dept. of Pharmacology, Uttara Adhunik Medical College, Dhaka
}

\begin{abstract}
The present study has been undertaken to find out the gastro-protective effect of aqueous extract of Azadirachta indica on ethanol induced gastric lesion in rats. To demonstrate this effect : some parameters of gastric damage -such as number of lesions, lesions length, lesions breadth, lesions area, lesions index and percent inhibition was chosen. In addition, histological features of rat stomach were also examined to confirm gastric damage and to determine the extent. The rats were provided with aqueous extract of Azadirachta indica (300mg $/ \mathrm{kg}$ body wt) orally by gastric tube. After $12 \mathrm{hrs}, 1 \mathrm{ml}$ absolute ethanol were orally administered to all groups by gastric tube. After 60 mins of administration, all rats were sacrificed. Rats pretreated with aqueous extract of Azadirachta indica (300 $\mathrm{mg} / \mathrm{kg}$ body wt) showed significant decrease in stomach damage both macroscopically and microscopically as compared to control. It is observed that aqueous extract of Azadirachta indica has gastroprotective effect. Therefore, aqueous extract of Azadirachta indica can be used to prevent gastric ulcer.
\end{abstract}

Keywords: Gastroprotective, Azadirachta Indica (Neem)

(Bangladesh J Physiol Pharmacol 2012;28(1\&2):10-14.)

\section{INTRODUCTION}

A peptic ulcer, also known as PUD or peptic ulcer disease, is the most common ulcer of an area of the gastrointestinal tract that is usually acidic and thus extremely painful. It is defined as mucosal erosions equal to or greater than $0.5 \mathrm{~cm}$. As many as $70-90 \%$ of such ulcers are associated with Helicobacter pylori, a spiralshaped bacterium that lives in the acidic environment of the stomach, however, only $40 \%$ of those cases go to a doctor. Ulcers can also be caused or worsened by drugs such as aspirin, ibuprofen, and other NSAIDs. Four times as many peptic ulcers arise in the duodenum-the first part of the small intestine, just after the stomach-as in the stomach itself. About $4 \%$ of gastric ulcers are caused by a malignant tumor, so multiple biopsies are needed to exclude cancer.A history of heartburn, gastroesophageal reflux disease (GERD) and use of certain forms of medication can raise the suspicion for peptic ulcer. Medicines associated with peptic ulcer include NSAID (non-steroid anti-inflammatory drugs) that inhibit cyclooxygenase, and most glucocorticoids (e.g. dexamethasone and prednisolone). ${ }^{1}$

The timing of the symptoms in relation to the meal may differentiate between gastric and duodenal ulcers.

Address for correspondence: Dr. Md. Rifayet Rahman, Deptartment of Pharmacology, Green Life Medical College, Dhaka. Email: rifayetrahman@yahoo.com
A gastric ulcer would give epigastric pain during the meal, as gastric acid production is increased as food enters the stomach. Symptoms of duodenal ulcers would initially be relieved by a meal, as the pyloric sphincter closes to concentrate the stomach contents, therefore acid is not reaching the duodenum. Duodenal ulcer pain would manifest mostly 2-3 hours after the meal, when the stomach begins to release digested food and acid into the duodenum. $\mathrm{H}_{2}$ blocker (Ranitidine), proton pump inhibitor (Omeprazole) provides relief of peptic ulcers, heartburn, indigestion and excess stomach acid and prevention of these symptoms. ${ }^{2,3}$

Herbs contain a large number of naturally occurring chemicals that have biological activity and compounds from plants that are used to produce reliable pharmaceutical drugs. Herbalism does however support holistic treatment, with prevention of disease being as important as the treatment of a particular illness. Another benefit of choosing herbal medicines is that a profound transformation in health can be achieved, without the danger of the inherent side effects common in drug-based medication. ${ }^{4}$

Medicinal plants are part and parcel of human society to combat diseases, from the dawn of civilization. Azadirachta indica (syn. Melia azadirachta) is well known in the subcontinent and its neighbouring countries for more than 2,000 years as one of the most 
versatile medicinal plants having a wide spectrum of biological activity. Azadirachta indica is popularly known as Indian neem (margosa tree) or Indian lilac. Azadirachta indica is an evergreen tree, cultivated in various parts of the Indian subcontinent. Azadirachta indica has been extensively used in ayurveda,unani and homoeopathic medicine and has become a cynosure of modern medicine. The Sanskrit name of the neem tree is 'Arishtha' meaning 'reliever of sickness'and hence is considered as 'Sarbaroganibarini'. The tree is still regarded as 'village dispensary' in the subcontinent. The importance of the neem tree has been recognized by the US National Academy of Sciences, which published a report in 1992 entitled 'Neem - a tree for solving global problems'.5,6

The bark, leaves, and seeds of Azadirachta indica are used to make medicine. Less frequently, the root, flower, and fruit are also used. ${ }^{7}$ Azadirachta indica (neem) leaf is used for leprosy, eye disorders, stomach upset, loss of appetite, skin ulcers, diseases of the heart and blood vessels (cardiovascular disease), fever, diabetes, gum disease (gingivitis), and liver problems. The leaf is also used for birth control and to cause abortions. The bark is used for malaria, stomach and intestinal ulcers, skin diseases, pain, and fever. ${ }^{8}$ The flower is used for reducing bile, controlling phlegm, and treating intestinal worms. The fruit is used for haemorrhoids, intestinal worms, urinary tract disorders, bloody nose, phlegm, eye disorders, diabetes, wounds, and leprosy. Neem twigs are used for cough, asthma, hemorrhoids, intestinal worms, low sperm levels, urinary disorders, and diabetes. People in the tropics sometimes chew neem twigs instead of using toothbrushes. The seed and seed oil are used for leprosy and intestinal worms. They are also used for birth control and to cause abortions. The stem, root bark, and fruit are used as a tonic and astringent. Some people apply neem directly to the skin to treat head lice, skin diseases, wounds, and skin ulcers; as a mosquito repellent; and as a skin softener. Inside the vagina, neem is used for birth control. Neem is also used as an insecticide. ${ }^{9}$

Animal studies published in Inflammopharmacology had shown that Azadirachta indica (neem) bark works by protecting the stomach's mucous lining and preventing oxidative damage by blocking lipid animal house in the department of Pharmacology of Dhaka Medical College. They were allowed to feed on standard laboratory diet and to drink water ad libitum.

\section{Plant material}

Azadirachta indica was collected from local market, Dhaka. Plant material was dried under shade at temperature less than $40^{\circ} \mathrm{C}$. The plant was authenticated by National Herberium (access no. 36526), Mirpur, Dhaka.

\section{Preparation of aqueous extract of Azadirachta indica}

Aqueous extract of Azadirachta indicawas prepared by mixing $15 \mathrm{gm}$ of dry powder with $100 \mathrm{ml}$ of sterile distilled water in a round bottom flask with occasional shaking. The extract was then filtered through a muslin cloth for coarse residue and finally through Whatman no 1. filter paper and kept in airtight amber coloured container. ${ }^{11}$

\section{Animal Experimentation:}

The experiment was divided into two parts: ExperimentI and Experiment-II.

\section{Experiment-I:}

This part of the experiment was carried out to demonstrate the effect of vehicle (distilled water) and aqueous extract of Azadirachta indica on gastric in experimental rats. It was comprised of 18 rats which was divided into 3 groups each having 6 rats. Groups were labeled as Group A and Group B and Group C.

Group A: This group served as control group for ethanol treated group and they were provided with distilled water ( $5 \mathrm{ml} / \mathrm{kg}$ body wt) orally by gastric tube.

Group B: This group were provided with distilled water ( $5 \mathrm{ml} / \mathrm{kg}$ body wt) and $1 \mathrm{ml}$ of absolute ethanol orally by gastric tube.

Group C: This group were provided with distilled water ( $5 \mathrm{ml} / \mathrm{kg}$ body wt) and aqueous extract of Azadirachta indica (300mg $/ \mathrm{kg}$ body $\mathrm{wt}$ ) orally by gastric tube. ${ }^{11}$ Twelve hours after the administration, the animals were sacrificed. The gastro-toxicity was evidenced by number of lesions, lesions length, lesions breadth, lesions area and lesions index of experimental rats.

Experiment II: This was comprised of total 18 rats. They were divided into 3 groups each containing 6 rats, lebeled as Group D ,Group E and Group F. This part of the experiment was carried out to demonstrate the effect of pretreatment with aqueous extract of Azadirachta indica and omeprazole on ethanol induced gastric ulcer in experimental rats.

Group D:This group was served as control group for extract treated groups and they were provided with distilled water ( $5 \mathrm{ml} / \mathrm{kg}$ body $\mathrm{wt}$ ) orally by gastric tube.

Group E: They were served with aqueous extract of Azadirachta indica orally by gastric tube.

Group F: They were served with omeprazole suspension ( $20 \mathrm{mg} / \mathrm{kg}$ body wt) orally by gastric tube.

After $12 \mathrm{hrs}, 1 \mathrm{ml}$ absolute ethanol was orally administered to all groups by gastric tube. After 60 mins of administration,all rats were sacrificed.

\section{Collection of the stomach}

Abdomen was opened by " $T$ " incision which is a vertical incision from xiphoid process to the upper part of 
symphysis pubis and a transverse incision extending 2 $\mathrm{cm}$ laterally on each side from top to vertical line. The stomach was separated from the rest of the small intestine. The stomach was opened along their greater curvature and gently rinsed under running tap water and was spread on a paraffin plate. Lesions in the glandular part of the stomach was observed with the help of dissecting microscope grossly $(10 \mathrm{x})$ with a square grid eyepiece to access the formation of ulcers. peroxidation and scavenging the free radicals that are a major cause of ulcers. ${ }^{10}$

The present work has therefore been taken to investigate the gastro-protective effect of aqueous extract of Azadirachta indica on ethanol induced gastric lesion in rats. Clinical investigation of this natural product would reveal better potentiality of Azadirachta indica in alleviating peptic ulcer.

\section{MATERIALS AND METHODS}

The study was carried out in the Department of Pharmacology of Dhaka Medical College from July 2011 to June 2012.

\section{Animal Housing:}

The experiments were carried out on 36 Swiss albino rats of 8-10 weeks and weighing 150-200 gm were purchased from the Animal House of International Centre for Diarrhoeal Diaease and Research, Bangladesh (ICDDR,B) Mohakhali,Dhaka.The rats were kept in metallic cages in the well ventilated

\section{Parameters studied Morphological parameters}

1. Number of lesion per rat in each group.

2. Individual lesion length and breadth in millimeter for each group.

3. Individual lesion area (length $\mathrm{x}$ breadth) in square millimeter for each group.

4. Mean ulcer index (sum of lengths of all lesions in each stomach) in millimeter for each group.

\section{Histological parameters}

Degree of damage was determined depending on the extent of involvement of lesion in stomach.

\section{Gross and microscopic examination and measurement of the morphological lesions}

The mucosa was washed in running tap water. Then the whole mucosa of the stomach of each rat was examined very carefully with the help of dissecting microscope $(x 20)$ with the aid of square grid eyepiece (1mm square) The ulcers were counted with the help of a hand lens ( 5 times magnification power) and the visible big lesions were measured with the help of hand lens and millimeter scale. Occulomicrometer was used for the examination of the mucosal surface and for the measurement of small lesion length, breadth and area. The graduation of occulomicrometer was standardized by comparing those with the markings of the stage micrometer following way-

When one magnification was used:

10 graduation of occulomicrometer $=1 \mathrm{~mm}$ of stage micrometer

Or 1 graduation of occulomicrometer $=0.1 \mathrm{~mm}$ of stage micrometer

Similarly with two (x2), four (x4) and ten (x10) magnifications, 1 graduation of occulomicrometer was equal to $0.05,0.025$, and 0.01 respectively. The maximum length, breadth and area of each lesion was measured and mean lesion area and mean ulcer index per rat in each group was calculated and used in lesion index for each group.

The ulcer index or lesion index (UI) was determined as the sum of length of all gastric lesions in $\mathrm{mm}$ for each stomach and the inhibition percentage was expressed by the following formula

Inhibition percentage $(\% 1)=[(\mathrm{UI}$ control $-\mathrm{UI}$ treated)/UI control] x 100

\section{Histological examination:}

The stomach tissue samples were fixed in $10 \%$ buffered formalin solution over night and then processed in an automated tissue processor. Stomach tissues were embedded in paraffin and subsequently sectioned by a microtome and stained with Haematoxyline and Eosin stain. Each section was examined by light microscope with magnification of $x 10$, x40 and x100 (oil immersion).

\section{Gastric damage was classified as follows:}

0 -Degree damage :Normal mucosa and other coats.

1-Degree damage :Inflammatory changes in the lamina propria of mucosa.

2-Degree damage : Sloughing of lining epithelium, but gastric pit epithelium is intact.

3-Degree damage :Degeneration of pit epithelium with or without beginning of degenerative process in glandular epithelium, but not completed.

4-Degree damage :Partial necrosis of gastric glands but erosion is limited to mucous coat.

5-Degree damage :Sloughing of the whole thickness of mucous coat but there is no perforation.

6-Degree damage :Perforation.

Photography of the specimens and photomicrography of the histological sections:

Just after the sacrifice of the animals the organs were collected, thoroughly washed and cleaned in tap water and photographed. Similarly slides of the selected areas of tissues were prepared and evaluation of the slides had been done. The selected fields in the slides were microphotographed by a special microscopic device at the photographic section of BCSIR. The negative were developed and printed. 


\section{Data collection and analysis:}

All relevant information's for each rat was recorded in a redesigned data collection sheet. Collected data were screened and compiled and sorted using MS excel. All data were recorded in tabulated form and the result was expressed as Mean $(+\mathrm{SD})$.

Table I

Effect of aquoeus extract of Azadirachta indica on mean number of lesions, mean lesions length, mean lesions breadth, mean lesions area and lesions index on group $A$ and group $B$

\begin{tabular}{l|ccccc}
\hline & $\begin{array}{c}\text { Mean number } \\
\text { of lesions }\end{array}$ & $\begin{array}{c}\text { Mean lesions } \\
\text { length }\end{array}$ & $\begin{array}{c}\text { Mean lesions } \\
\text { breadth }\end{array}$ & $\begin{array}{c}\text { Mean lesions } \\
\text { area }\end{array}$ & $\begin{array}{c}\text { Lesion } \\
\text { index }\end{array}$ \\
\hline $\begin{array}{l}\text { Group A } \\
n=6\end{array}$ & 0 & 0 & 0 & 0 & 0 \\
$\begin{array}{l}\text { Group C } \\
n=6\end{array}$ & 0 & 0 & 0 & 0 & 0 \\
\hline
\end{tabular}

Table II

Showing the effect of pre treatment of aqueous extracts of Azadirachta indica on mean number of lesions, mean lesions length, mean lesions breadth, mean lesions area and lesions index on each group in experiment II

\begin{tabular}{l|lll}
\hline & $\begin{array}{l}\text { Group D } \\
n=6\end{array}$ & $\begin{array}{l}\text { Group E } \\
n=6\end{array}$ & P value \\
\hline Mean number of lesions & $5.16 \pm 1.16$ & $3.0 \pm 1.26$ & $<0.01$ \\
Mean lesions length & $8.46 \pm 3.04$ & $2.75 \pm 0.77$ & $<0.01$ \\
Mean lesions breadth & $2.70 \pm 1.29$ & $0.48 \pm 0.33$ & $<0.001$ \\
Mean lesions area & $23.84 \pm 28.46$ & $2.32 \pm 0.99$ & $<0.001$ \\
Lesion index & $32.92 \pm 10.40$ & $5.74 \pm 2.16$ & $<0.001$ \\
\hline
\end{tabular}

\section{DISCUSSION}

The present study was carried out to evaluate the gastro-protective effect of aqueous extract of Azadirachta indica on experimentally induced gastric ulcer in rats. For this purpose, effect of aqueous extract of Azadirachta indica were demonstrated both in normal, untreated and ethanol induced gastric damage in rats.In addition,histological studies of rats stomach following administration of aqueous extract of Azadirachta indica were also done.

In the present study, Absolute ethanol was used as agent to induce stomach ulcer in rats. The dose and routes of administration was selected according to Mequanente and Mahmood. ${ }^{12}$ Ethanol induced gastric ulcers are commonly used for evaluation of anti-ulcer activity. Absolute ethanol penetrates the gastric mucosa very quickly, which explains why 30 minutes was sufficient for developing gastric lesions in rats. ${ }^{13}$ Mequanente and Mahmood also in their study showed that acute per oral administration of absolute ethanol $(5.0 \mathrm{ml} / \mathrm{kg})$ to fasted rats produced extensive necrosis of gastric mucosa.

The experiments have shown that Azadirachta indica extract has gastroprotective potentials at the 300 $\mathrm{mg} / \mathrm{kg}$ dose given 12 hours before the administration of $1 \mathrm{ml}$ of absolute ethanol. Ofusori earlier affirmed systemic presence of free radicals to be synonymous to ill health leading to weight loss. ${ }^{14}$ Istav Szelehji showed that ethanol-induced gastric injury is associated with the significant production of free radicals leading to increased lipid peroxidation which causes damage to cell and cell membranes. ${ }^{15}$ The antioxidant properties of Azadirachta indica together with some other factors yet to be established. Chattopadhyay in a similar work revealed that membrane damage by hydroxyl radical as measured by lipid peroxidation in stress ulcer is significantly blocked by neem extract. ${ }^{10}$ The ethanolinduced gastric mucosal damage has also been known to be associated with the significant reduction in the non-protein sulphyldryl concentration in cultured rat gastric mucosa cells. The cytoprotective mechanism of Azadirachta indica extract $(300 \mathrm{mg} / \mathrm{kg}$ ) against ethanolinduced mucosal injury in rats in this investigation may also be due to a reduction in the total acidity as well as an increase in gastric wall mucus. The gastric mucus plays an important role in protecting gastric mucosa against ulcerogens and facilitates the repair of the damaged gastric epithelium. The mucus gel adhering to the gastric mucosal surface protects the underlying epithelium against acid and necrotizing agents, like 
ethanol. Allen and Guardia, in their earlier studies have shown that restoration of damaged gastric epithelium improves the formation of gastrointestinal mucus, which protects gastric mucosa against necrotizing agents. ${ }^{16,17,18}$ There was also a regeneration and maintenance of the cytoarchitecture of the entire gastric mucosa in the damaged regions. These findings buttress and confirm the cytoprotective potential of aqueous extract of Azadirachta indica.

\section{CONCLUSION}

The observation and results of this study provide a rationale for use of Azadirachta indica in the development of a new drug, for treatment and prevention of peptic ulcer disease.In conclusion this study establishes that Azadirachta indica (neem) extract has gastroprotective ability following consumption of ethanol. It recommends further study regarding pharmacokinetics, pharmacodynamics, toxicolgy and posology of extract of Azadirachta indica (neem) to develop it as a useful antiulcer agent for human.

\section{REFERENCES}

1. Cullen DJ, Hawkey GM, Greenwood DC, Peptic ulcer bleeding in the elderly: relative roles of Helicobacter pylori and non-steroidal anti-inflammatory drugs. Division of Gastroenterology, University Hospital,Nottingham, UK 1997; 41 (4): 459-62.

2. Johannessen T, Peptic ulcer disease. Journal of Gastroenterology 2001; 88 (11): 1123-28.

3. Salih, B, M Fatih Abasiyanik, Nizamettin Bayyurt, Ersan Sander. H. pylori infection and other risk factors associated with peptic ulcers in Turkish patients: A retrospective study. World Journal of Gastroenterology 2007; 13 (23): 3245-8.

4. Barnes, J, Ernst, Edzard. Traditional herbalists' prescriptions for common clinical conditions: A survey of members of the UK National Institute of Medical Herbalists. Phytotherapy research 1998;12 (5): 369.

5. Castleman M, The New Healing Herbs: The Classic Guide to Nature's Best Medicines Featuring the Top 100 Time-Tested Herbs. Rodale 2001: 15

6. Walter J,Craig D, Medieval contributions to the search for truth in clinical medicine. Perspectives in Biology and Medicine 2000;43 (4): $530-540$.
7. Upadhyay S, Dhawan S, Sharma M, Anti fertilty effect of neem .General Pharmacology 1994;49, 161-169.

8. Ray A, Banerjee BD, and Sen P,Immuno stimulant effect of neem compound .Journal of Pharmacology 1996; 34, 698-701.

9. Rao BS, Nazma and Rao, Neem compounds-a study.Indian Journal Medical Research 1977; 46, 14-16.

10. Chattopadhyay I, Nandi B, Chatterjee R, Biswas K, Bandyopadhyay $U$, Banerjee RK.Mechanism of antiulcer effect of Neem (Azadirachta indica) leaf extract: effect on $\mathrm{H}+-\mathrm{K}+-\mathrm{ATPase}$, oxidative damage and apoptosis. Department of Physiology,Indian Institute of Chemical Biology,Kolkata,India 2004;12(2):153-76.

11. Bandyopadhyay U, Biswas $K$, Chatterjee R, Bandyopadhyay $D$, Chattopadhyay I,Ganguly CK, Chakraborty T, Bhattacharya K, Banerjee RK.Department of Physiology, Indian Institute of Chemical Biology. Gastroprotective effect of Neem (Azadirachta indica) bark extract: possible involvement of $\mathrm{H}(+)-\mathrm{K}(+)$-ATPase inhibition and scavenging of hydroxyl radical 2002;71(24):284565

12. Mequente S,Makhonnen E,Asfaw debella A.Gastroprotective effect of aqueous extract of trigonella feonum-gracum And linum ussitatisssimum seed extracts in mice.Pharmacology online 2006;2:324-334

13. Liu CF, Lin CC, Lin MH,Lin YS, Lin SC.Cytoprotection by propolis ethanol extract of acute absolute ethanol-induced gastric mucosal lesions.Journal of Chinese Medicine 2002;30(2):245-54

14. David A Ofusori , Benedict A Falana,Taiwo A,Sunday A,Gideon B,Gastroprotective effect of aqueous extract of Azadirachta indica on induced gastric lesion in rats. Department of Anatomy and Cell Biology, Faculty of Basic Medical Sciences, Obafemi Awolowo University, Ile-Ife, Osun-State, Nigeria. Int J Biol Med Res 2010; 1(4): $219-222$

15. Szelehji I,Brune K. Possible role of oxygen free radicals in ethanol induced gastric mucosal damage in rats. Digestive Disease Science.1988;33:865-71

16. Garg GP, Nigam SK, Ogle CW, Antiulcer effects of the leaves of the neem tree of Pharmacology, Faculty of Medicine, University of Hong Kong $1993 ; 59(3): 215-7$.

17. Mahmood AA,Sidik $K$ and Salmah I.Antiulcer and gastro-protective effects of honey in combination with Trigonella foenum seeds extract on experimentally induced gastric ulcer in rats. International journal of Molecular medicine and advanced science 2005;1(3):225-9

18. Dorababu M, Prabha T, Priyambada S, Agrawal VK,Aryaa NC, Goe RK. Effect of Azadirachta indica on gastric ulceration and healing of Bacopa monnierang in experimental NIDDM rats. Indian J Exp Biol 2004; 42: 389-397. 